\title{
5 YEARS OF MEASUREMENT OF ELECTROMAGNETIC EMISSION IN WEST BOHEMIAN SEISMOACTIVE REGION
}

\author{
Petr KOLÁř \\ Institute of Geophysics, Academy of Sci. of the Czech Rep., Bočni II/1401, 14131 Praha 4, Czech Republic
}

Corresponding author's e-mail: kolar@ig.cas.cz

\begin{tabular}{l} 
ARTICLE INFO \\
\hline Article history: \\
Received 10 September 2013 \\
Accepted 14 February 2014 \\
Available online 3 March 2014 \\
\hline
\end{tabular}

\section{Keywords:}

Electromagnetic emission observation

West Bohemian earthquake swarms

\begin{abstract}
In the previous work we discovered a possible correlation between seismic activity in West Bohemia (Czech Rep.) and electro-magnetic emission (hereafter EME) during earthquake swarm in 2008 year (frequency range of observation: $0.2-10 \mathrm{~Hz}$ ). Since then the EME observation has been continuing for 5 years. We present new results of EME observation during two consecutive swarms (in years 2011 and 2013) - we have to conclude, that the statistical correlation observed during 2008 year swarm was observed only partly and weakly for 2011 year swarm and it was not confirmed for the 2013 year swarm. We are not able to explain observed fact (due to heuristic and statistical character of original hypotheses), it can be an accidental correlation (in 2008 year), but the effect could also vanish for weaker swarms (i.e. for 2011 year and especially for 2013 year), or it could be an effect of different medium property round the hypocenters (the seismic activity migrates to the north with time).
\end{abstract}

\section{INTRODUCTION}

Speculations about link between seismic activity and electromagnetic emission (hereafter EME) can be traced back in the literature for decades. Despite of such a long history, the validity of the link has not been clearly verified, the observations are often unique, uncertain, the phenomenon is handled only quantitatively, etc. In the present paper we describe 5 years of measurement of EME in West Bohemian (Czech Rep.) seismoactive region. Activity in the region is characterized by repeated occurrence of seismic swarms. Our EME measurement (in range $0.2-10 \mathrm{~Hz}$ ) was started in Oct 2008, accidently at the beginning of a pronounced seismic swarm. Three pronounced swarms (in 2008, 2011 and 2013 years) occurred during 5 years period of EME measurement. Those data are subject of our analysis. Note that it has also occurred several micro-swarms which are not so far tested as a potential source of any EME effect.

Below we give a brief characterization of the region and of the relevant earthquakes swarms, as well as the description of the EME measurements, their processing and the judgement of the results.

\subsection{WEST BOHEMIA SEISMOACTIVE REGION}

Seismic activity in West Bohemia region is definitely the most important seismic phenomenon in the territory of the Czech Republic - Figure 1. The activity is characterized by reoccurrence of moderate size earthquakes swarms. The activity can be traced back for several centuries (historical written notices), the instrumental observation started in the region at the beginning of $20^{\text {th }}$ century, the modern observations can be dated since 1985 when the first two digital instruments were deployed. Now, the activity is continuously monitored by a seismic network WEBNET (wwwWEBNET, 2013), Horálek et al. (2000), Horálek et al. (2009) which actually operates over 20 stations (the actual number of station can vary as the net of permanent station can be extended by temporal ones during periods of higher activity or during experiments). The (seismic) data are subject of routine analysis (location, magnitude determination, etc.) as well as of numerous particular studies; the activity is investigated from seismic as well as non-seismic points of view. An overlook about investigated topics can be obtained e.g. from special issues of Studia Geophysica et Geodetica (2000, 2008, 2009) or from recent review by Fischer et al. (2013), as the most recent examples of variety of performed studies it can be mentioned e.g. Kolář (2010), Koláŕ et al. (2011), Kolář and Růžek (2012), Chum et al. (2012), Růžek et al. (2012).

Note, that also non-seismic phenomena are observed in the region and data are processed and/or correlated with seismic observations: see e.g. Špičák (2000), observation of $\mathrm{CO}_{2}$ emanation, (Faber et al., 2009), gravimetric measurements (Mrlina and Seidl, 2008, Mrlina et al., 2009), micro-network observation (Häge and Joswig, 2008), ionospheric observations (Chum et al., 2012, 2013). 


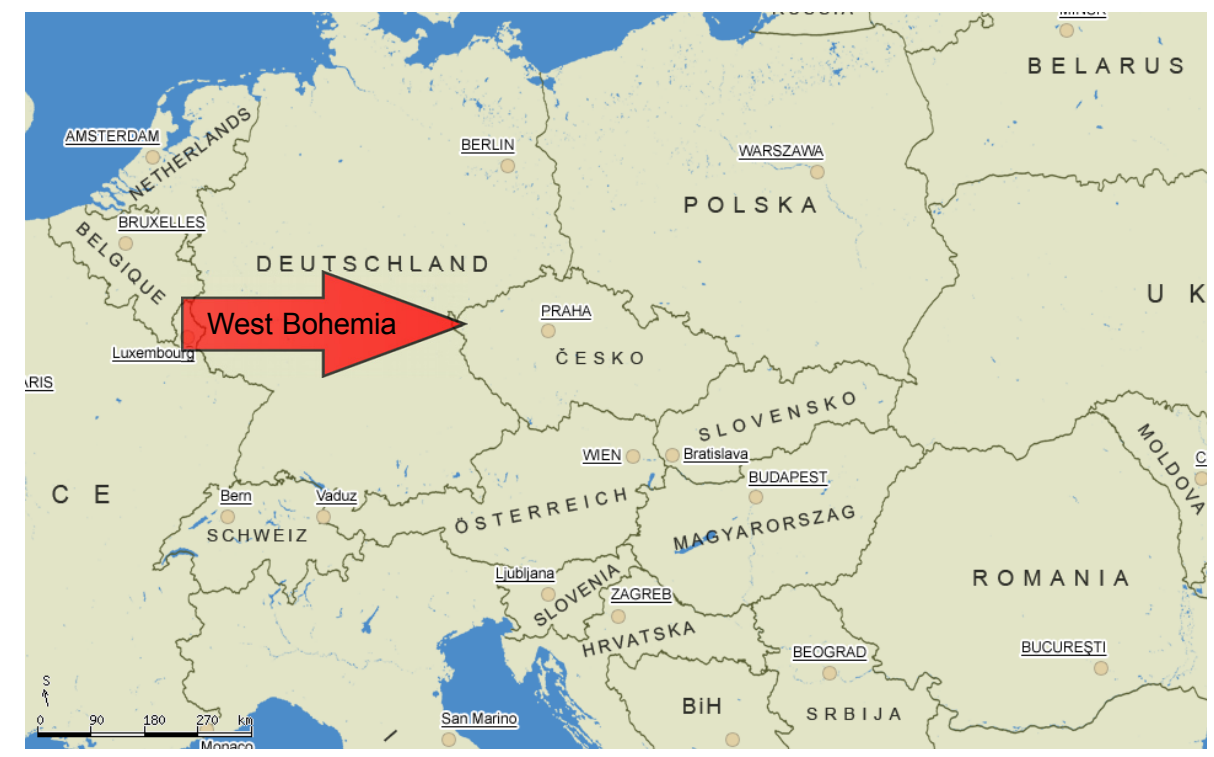

Fig. 1a Position of West Bohemia region in central Europe.

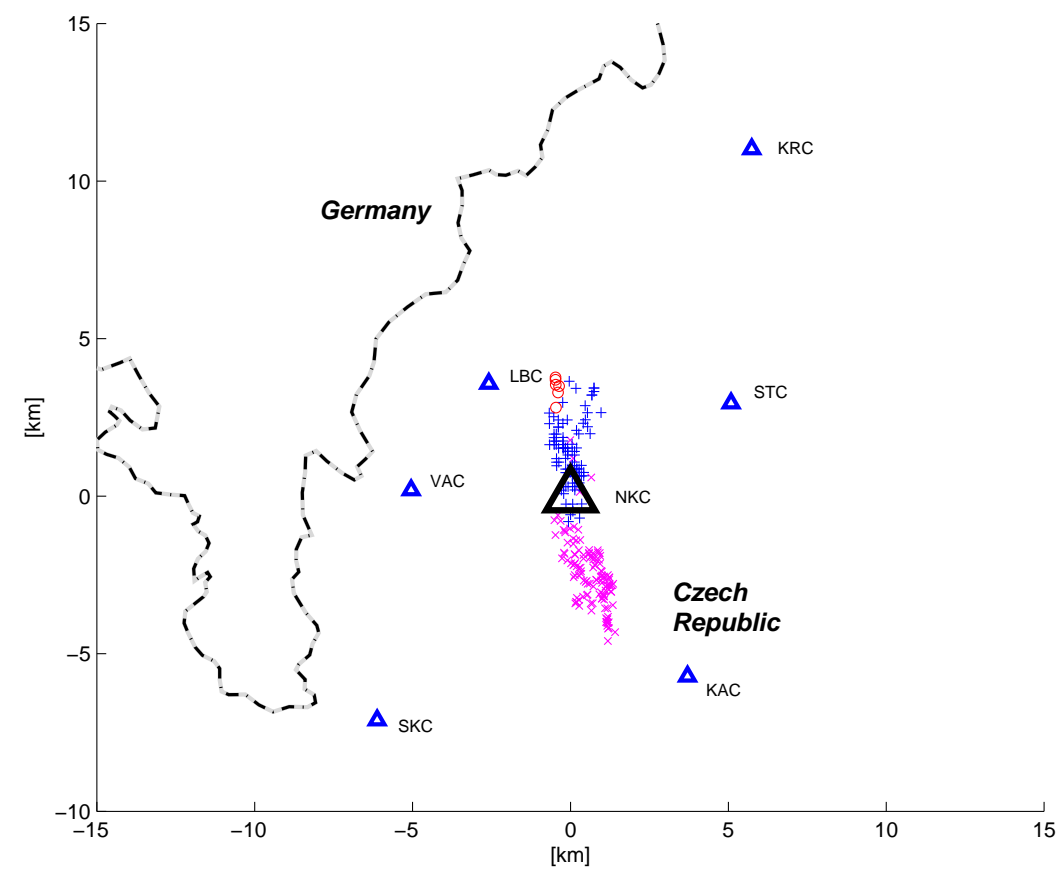

Fig. 1b West Bohemia earthquake swarms region. There are plotted the nearest stations of WEBNET network (triangles); station Nový Kostel (NKC), where the EME measurement is deployed, is marked by bigger triangle. There are plotted also epicenters of considered swarms (2008 'x'; 2011 '+'; 2013 'o') - for simplicity only processed evens from the swarms are plotted. The states border is marked by dashed line.

\subsection{EME MEASUREMENT IN WEST BOHEMIAN REGION}

Being inspired by numerous and long lasting references about binding seismic activity and electromagnetic phenomena (mention here just one example instead many: exhaustive reviews by Johnston, 1997), we started such measurement also in West Bohemia earthquake region with expectation that at least the stronger events (let say $\mathrm{Ml}>2$ ) can possibly generate such an effect. The used instrumentation was a compromise among theoretical expectations, practical possibilities and available instrumental equipment. We consequently designed and tested several approaches of observed data processing. 


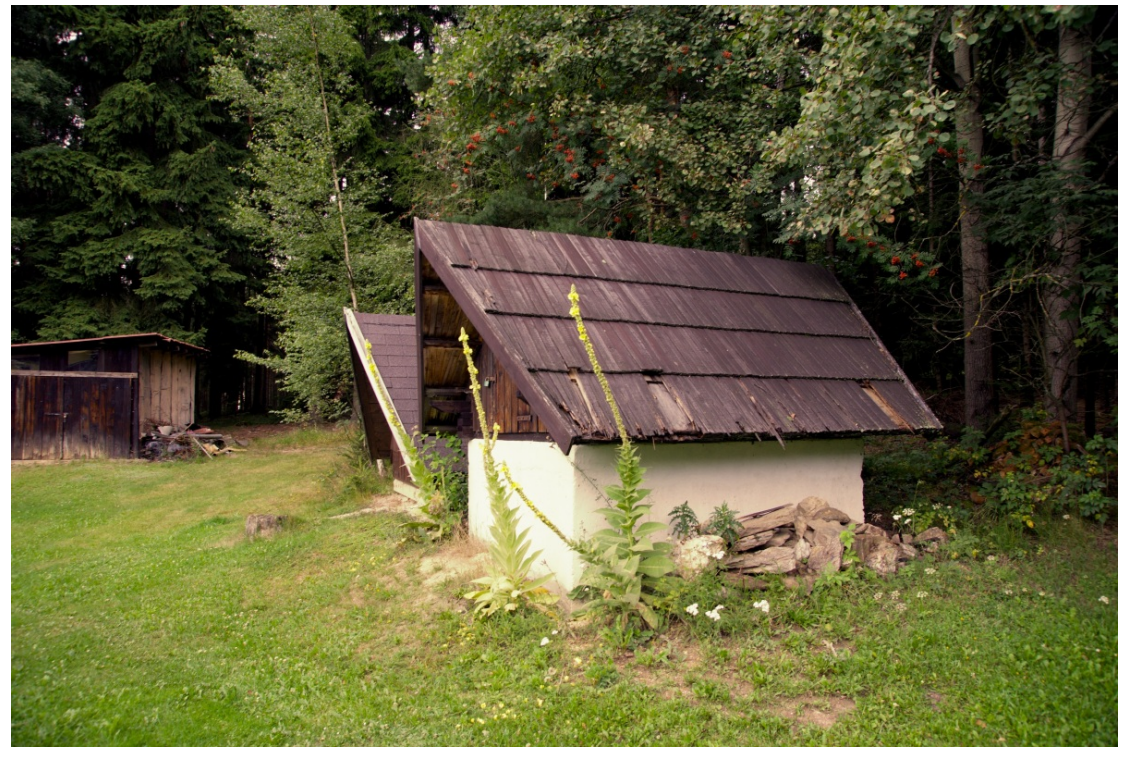

Fig. 2a Station Nový Kostel (NKC) - outdoor situation. The seismometers are situated in cca $5 \mathrm{~m}$ depth well, which is protected by "small chalet".

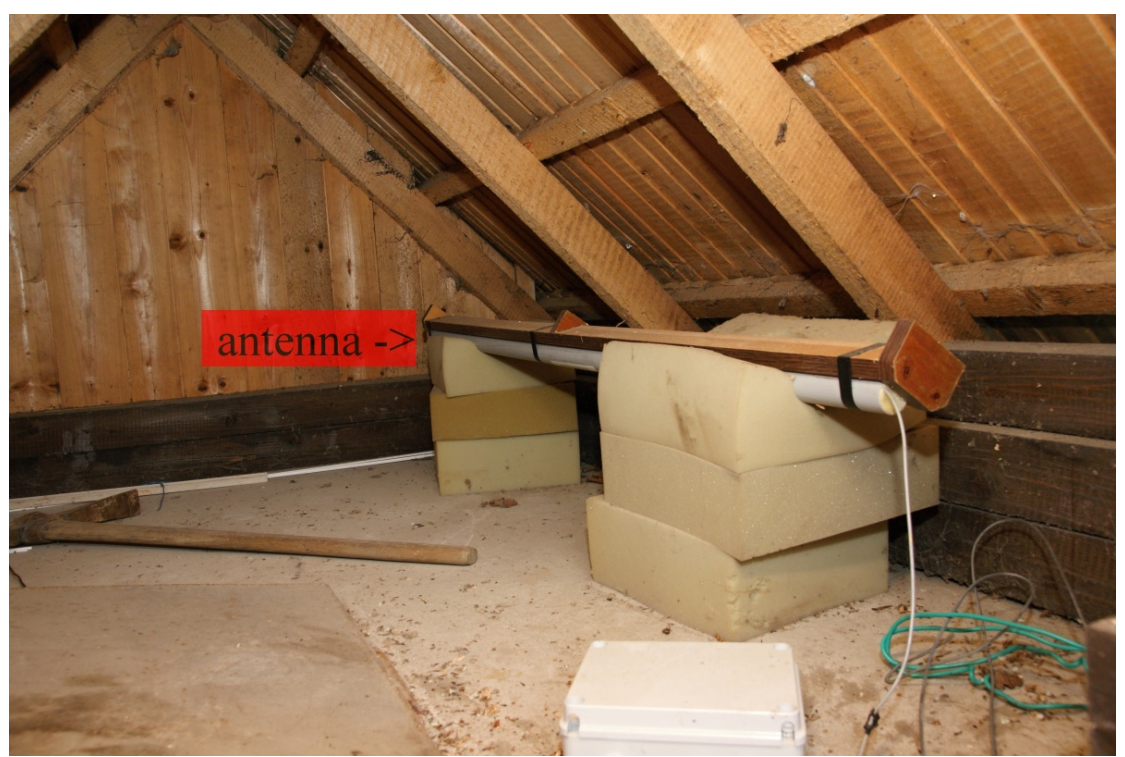

Fig. 2b The EME antenna is situated under the roof of "small chalet".

Note, that the references about the effect under the interest are either uncertain, unparalleled only (with no repetition of observation of the phenomenon), observation conditions are insufficiently described or the particular phenomenon is handled only qualitatively, etc. The effect itself comprise of the lights (St-Laurent et al., 2006; Losseva and Nemchikov, 2005), flashes, storms and ionosphere changes excited by large earthquakes (excitation is supposed to be transferred via the Earth's surface vibrated by surface waves; Guglielmi et al., 2006 a, b; Chum et al., 2012, 2013).

Our experiment had to been planned for some time and the measurement itself started in October 2008, accidently during an ongoing pronounced swarm. Therefore the potential correlation between seismic activity and EME signals could be tested immediately.

\section{EME INSTRUMENTATION AND RECORDED DATA}

We started our EME observation with an instrument composed from coil antenna, amplifier and digitizer. Coil antenna contains of about 20.000 turns with permealoid core, frequency range of the instrument is about $0.2-10 \mathrm{~Hz}$ with sampling rate $25 \mathrm{~Hz}$, continuous registration. The instrument was installed at the seismic station Nový Kostel (NKC), which is situated directly in the epicentral zone Figure 2. A part of the apparatus (a digitizer) was 
Table 1 Basic characteristic of processed swarms.

\begin{tabular}{llcccc}
\hline swarm & Aprox. duration & $\begin{array}{c}\text { Number of events } \\
\text { Ml }>0.5\end{array}$ & $\begin{array}{c}\text { Number of processed } \\
\text { events (Ml>1.8) }\end{array}$ & Ml max & Ml $_{\text {cum }}{ }^{2)}$ \\
\hline 2008 & 10 Oct 2008 - 05 Nov 2008 & $>20000$ & $47^{3)}$ & 3.8 & 4.30 \\
2011 & 23 Aug 2011 - 30 Dec 2011 & $>10000$ & 181 & 3.7 & 4.02 \\
2013 & 22 Apr 2013 - 23 May 2013 & cca 5000 & $21^{4)}$ & 2.3 & $2.78^{6)}$ \\
\hline
\end{tabular}

1) Only stronger events are supposed to excite EME effect, thus only thoses events are considered in the study.

2) Cumulative magnitude $\left(\mathrm{Ml}_{\text {cum }}\right)$ is used to characterize total size of the swarm. It is evaluated is such a way, that energy of each event is estimated (with used of standard Gutenberg-Richter magnitude-energy relation: $\log E=1.5 M l+11.8$ ), the energies are summed and (with used of inversion formula) $\mathrm{Ml}_{\text {cum }}$ is evaluated.

3) Only events after 15 Oct 2008, when the EME measurement started, are considered.

4) The bulletin of 2013 swarm is only preliminary, however all pronounced events are supposed to be already interpreted.

5) As the 2013 swarm is the weakest from all three considered swarms, the limit was lowered to Ml $>1.5$

6) The same as 4), but only some week events may be added to the bulletin and the $\mathrm{Ml}_{\text {cum }}$ value would not change significantly.

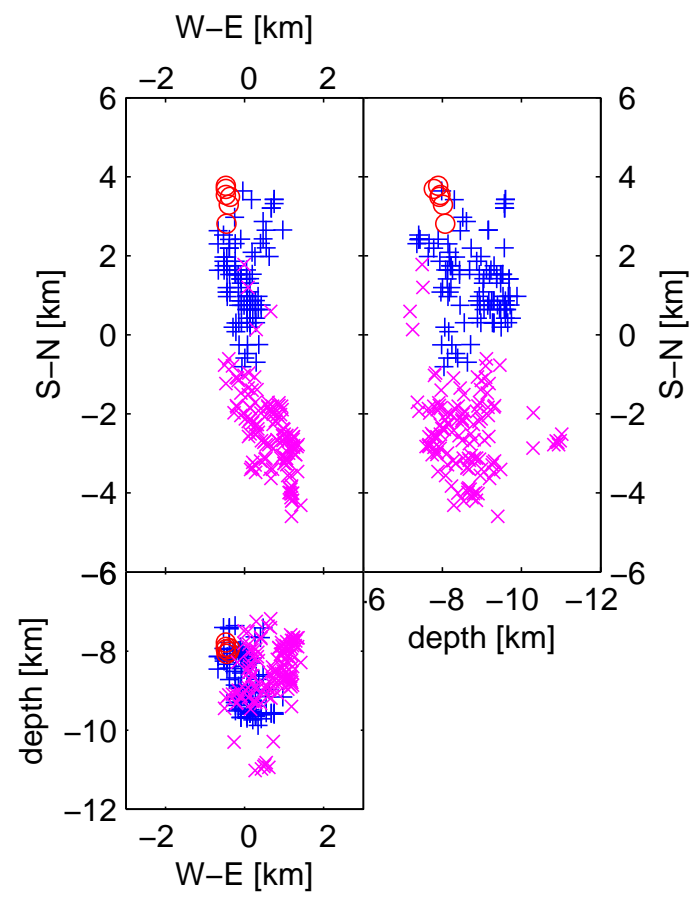

Fig. 3 Locations of processed events are plotted (swarm 2008 ' $x$ '; 2011 '+'; 2013 'o'). Three projections are used; upper left - horizontal projection, upper right vertical projection oriented in N-S direction, lower left - vertical projection oriented in W-E direction. The distances are given in $[\mathrm{km}]$, the origin is in station Nový Kostel (NKC). The figure shows that the seismic activity migrates to the north with the time.

destroyed by a summer storm in year 2010 and was replaced by a more modern version with sampling rate $50 \mathrm{~Hz}$.

During the period of observation (now more than 5 years lasting) occurred 3 pronounced seismic swarms, which were considered to be strong enough to potentially excite some EME activity. Brief overlook about theses swarms is given in Table 1 and in Figure 3. The results of processing of the data recorded during the 2008 swarm were already published in Koláŕ (2010).

\section{EME DATA MINING}

As already mentioned above, also the way of EME data processing had to be designed. The early analysis showed, that the instrument behave as a "poor quality" seismometer, i.e. there are strong signals which exactly correlate with $\mathrm{P}$ and/or $\mathrm{S}$ waves arrival at the station, we call this anomaly "microphone effect" (it was already documented in (Koláŕ, 2010)). We tested EME data on occurence of any signal at the time of earthquake outbreak (i.e. earthquake origin time), but no positive correlation 


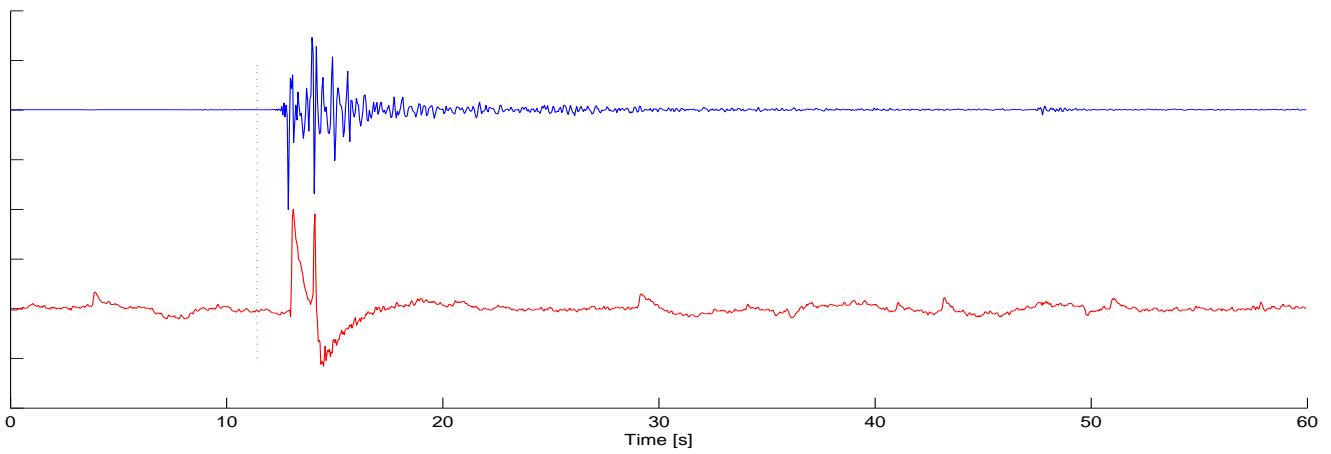

Fig. 4 An example of recorded EME signal (lower line) and corresponding seismic signal (upper line, both signals are normalized) at station NKC, event 28 Oct 2008, origin 08:30:13.1, Ml 2.4, Z component, $20 \mathrm{~Hz}$ sampling. The vertical line marks origin time of the event, the reaction of EME signal on arrival of seismic waves at the station is obvious.

As secondary extremes of EME signal cannot be directly interpreted, they are treated statistically in our study.
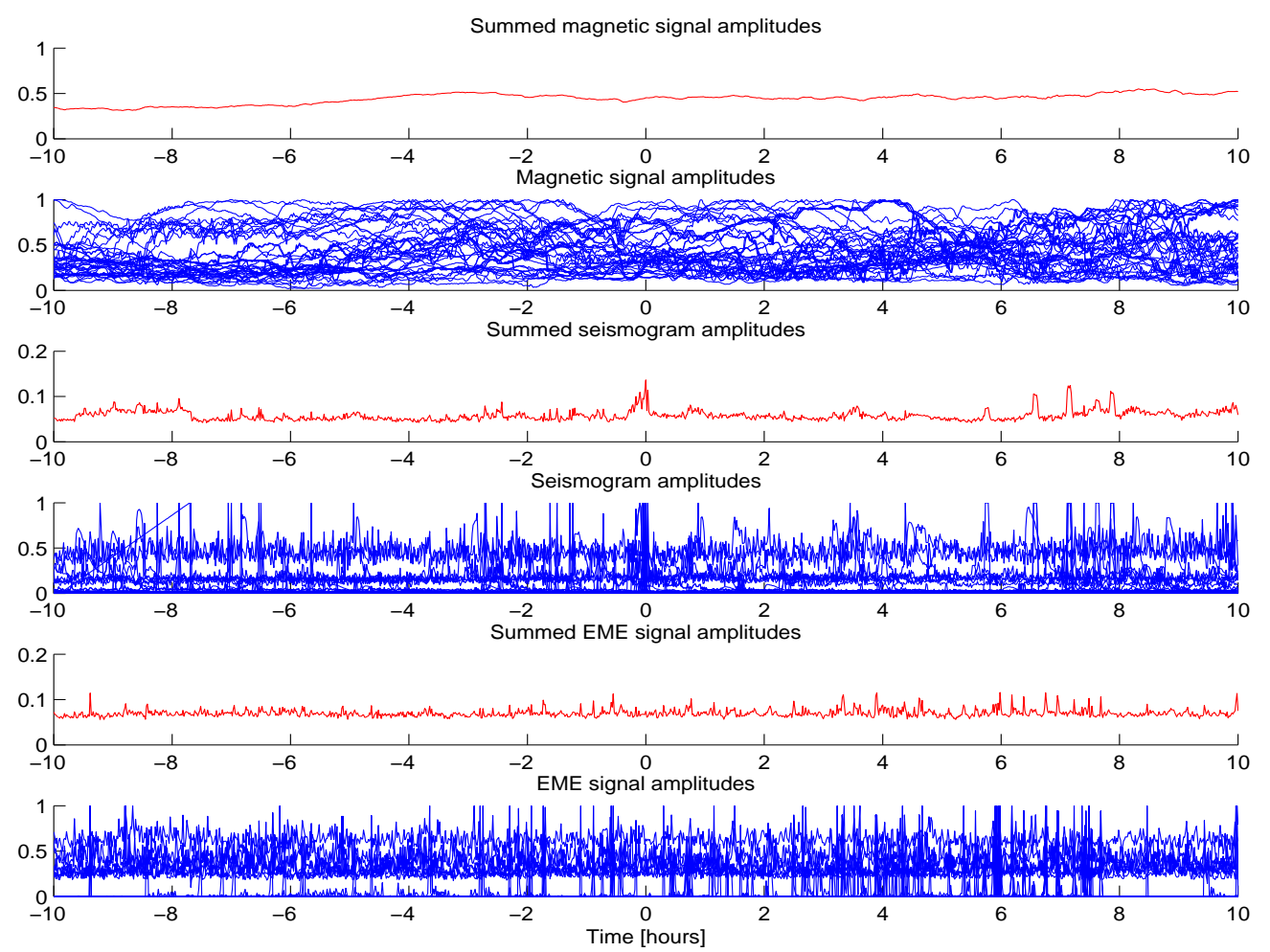

Fig. 5 An example data used for stacked long time analysis; from bottom to the top: EME signals for stacking, final stacked EME signal, corresponding seismograms for stacking and final stacked seismogram, corresponding magnetic signals for stacking and final stacked magnetic signal; data from 2008 swarm (47 events) are presented.

was observed neither directly in the data nor in their statistical stacked summation. An example of EME signal and corresponding seismic signal is given in Figure 4.

Further, being inspired by approach Georiadis et al. (2009), we concentrated on study of long term stacked parts of EME data. Original EME data are transformed into one minute amplitude average and then, with use of formula

$$
\operatorname{sumEME} E_{(-d t,+d t)}=\sum_{i=1 \cdot N} E M E_{(T 0 i-d t, T 0 i+d t)}
$$

are stacked. sumEME is the final stacked signal of length $2 \times d t, T O i$ is the origin time of $\mathrm{i}$-th event 
$(\mathrm{i}=1: \mathrm{N}), E M E_{(T 0 i-d t, T 0 i+d t)}$ is the particular interval of minutes averages of amplitudes of EME signal from time $T 0 i-d t$ to $\mathrm{T} 0 \mathrm{i}+d t$. The wavelet spectrum is calculated from the stacked signal sumEME; interval $d t$ was set to 10 hours in our study - an example of minute amplitude signals as well as stacked signals is given in Figure 5.

For the 2008 year swarm the method yielded interesting result, which indicated that there are some EME activity changes before and after the earthquakes: there is (i) an increase of EME activity from time -3 to 0 hours before the seismic event with a maximum in time -1 to -0.5 hour on periods 14 17 minutes, (ii) statistical gap of EME activity in time +1 to +2 hours after the seismic event and (iii) maximum of EME activity in time +4 hours after a seismic event - see Figure 6a (in colored appendix). All observed extremes appeared to be stable and robust. The results was published in Kolár in this work it was also shown that the effect is neither excited by other earthquakes accidently situated in the critical time delay, nor by the above mentioned microphone effect. We speculated, that the observed EME activity changes can be linked with an earthquake preparation and post event material relaxation. Data from 2011 and 2013 years swarms were processed in the same way. For 2011 year there are two narrow maxima on periods $2-6$ minutes: the first in time -2 hours, the late in time +4.5 hour, however these extremes are not too pronounced and would not been probably recognized if results from 2008 year swarm were not know - Figure 6b. For 2013 year swarm no relevant extremes were not found at all - Figure 6c.

Note, that also others ways of averaging or time intervals were tested. We also try e.g. to deconvolve EME signals from the swarm with use of signals out of the swarm. However none of such attempts led to any (positive) results.

As we already did for 2008 year swarm, the seismic data from station Nový Kostel were processed in the same way as EME data (i.e. they were calculated minute averages of the signal, corresponding intervals were stacked and wavelet spectrum was calculated). Results are in Figure 7 and confirm that the observed extremes of EME signals are not excited by seismic signal. In addition we processed data from magnetic observatory Budkov ${ }^{1}$ (again in the same way) to confirm that observed EME activity is not excited by global magnetic field. Results of this analysis are in Figure 8.

\section{RESULTS AND DISCUSSION}

As it follows from Figure 6a, wavelet spectrum from 2008 year swarm data shows extremes in EME data level, which can be interpreted in terms of an earthquake preparation, relaxation and healing (c.f. Kolár. 2010) and the effect was found to be qualitatively consistent with results published by Fraser-Smith et al. (1990) (quoted also in Johnston, 1997 and Koláŕ, 2010). However the effect can be hardly observed for swarm 2011 and is not observed for 2013 year swarm, when they are processed in the same way. As the interpretation of the effect of swarm 2008 year was heuristic, it is not possible to conclude to much more about nature of these effects. We may speculate either that the 2008 year result is simply an accident, or that the swarms in 2011 and 2013 years even if still pronounced, were weaker and weaker and that they were not strong enough to excite the effect. On the other hand, the effect observed in 2008 year swarm seemed to be rather excited by moderated events $(\mathrm{Ml} \sim 2)$ then with the strongest ones (see Kolár, 2010). The two later swarms, even if they are about similar location, were after all situated rather northerly (see Fig. 3) and the effect also could vanish when a swarm is located in possibly different medium.

To summarize: even if the EME measurement continues and a pronounced seismic activity occurred, the correlation of EME activity with seismic activity based on early analysis of the measurements practically was not confirmed.

We plan to continue our EME observations in the region. A measurement on higher frequencies $(0.8-8 \mathrm{kHz})$ has been started recently (at Nov 2013) and an observation on lower frequencies is under preparation. We will provide (upon a request) our EME data for any reasonable type of analysis.

\section{ACKNOWLEDGEMENTS}

The project of EME measurement in West Bohemian region has only partial direct official support and, therefore, all the work can be performed only due to enthusiasm and effort of the following people. Thanks goes to: J. Horálek, leader of WEBNET group, for spiritual, materialistic and financial support of the project, P. Jedlička for technical help, A. Boušková for kind providing WEBNET seismic bulletins and comments, F. Hruška, J. Baše, and J. Chum (all three from the Institute of Atmospheric Physics of Czech Acad. of Sci., department of Upper Atmosphere) for the construction of special coil antenna and technical help, J. Zedník for kind providing data from seismic station $\mathrm{NKC}$, J. Horáček for kind providing data from magnetic observatory Budkov.

The EME data analysis of 2011 and 2013 years swarms was partly supported by the grant P210/10/1728 (Ms. Z. Jechumtálová) of the Grant Agency of the Czech Republic.

\footnotetext{
${ }^{1}$ Magnetic observatory Budkov is situated in south Bohemia, cca $180 \mathrm{~km}$ to SE from Nový Kostel.
} 

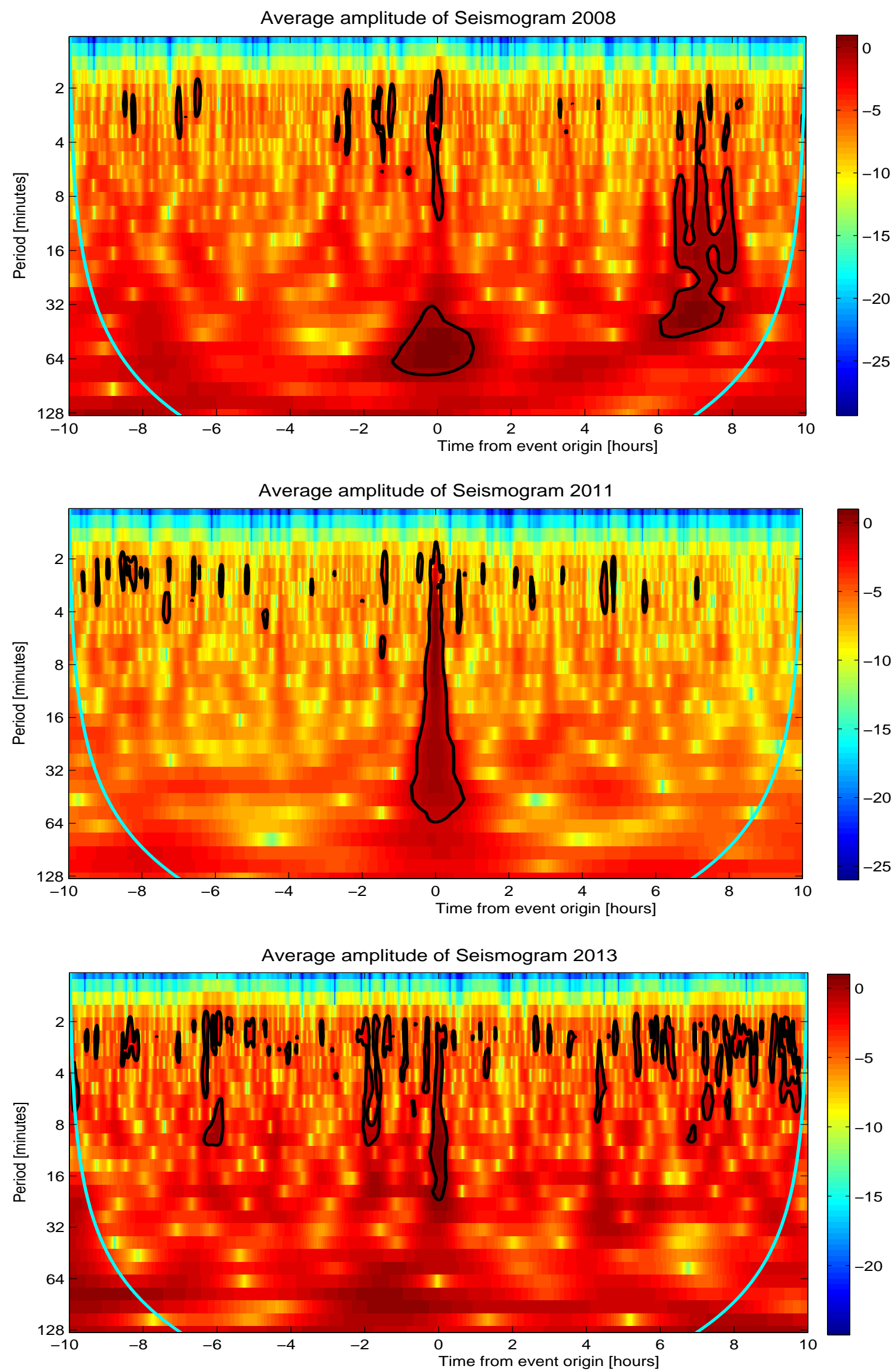

Fig. 7 The same as in Figure 6, but for seismic signals. There is pronounced maximum in time $=0$ (corresponding to the seismic events), but no other extremes corresponding to the EME extremes can be observed, which indicate that observed EME extremes are not excited by coincided arrivals of seismic waves. 

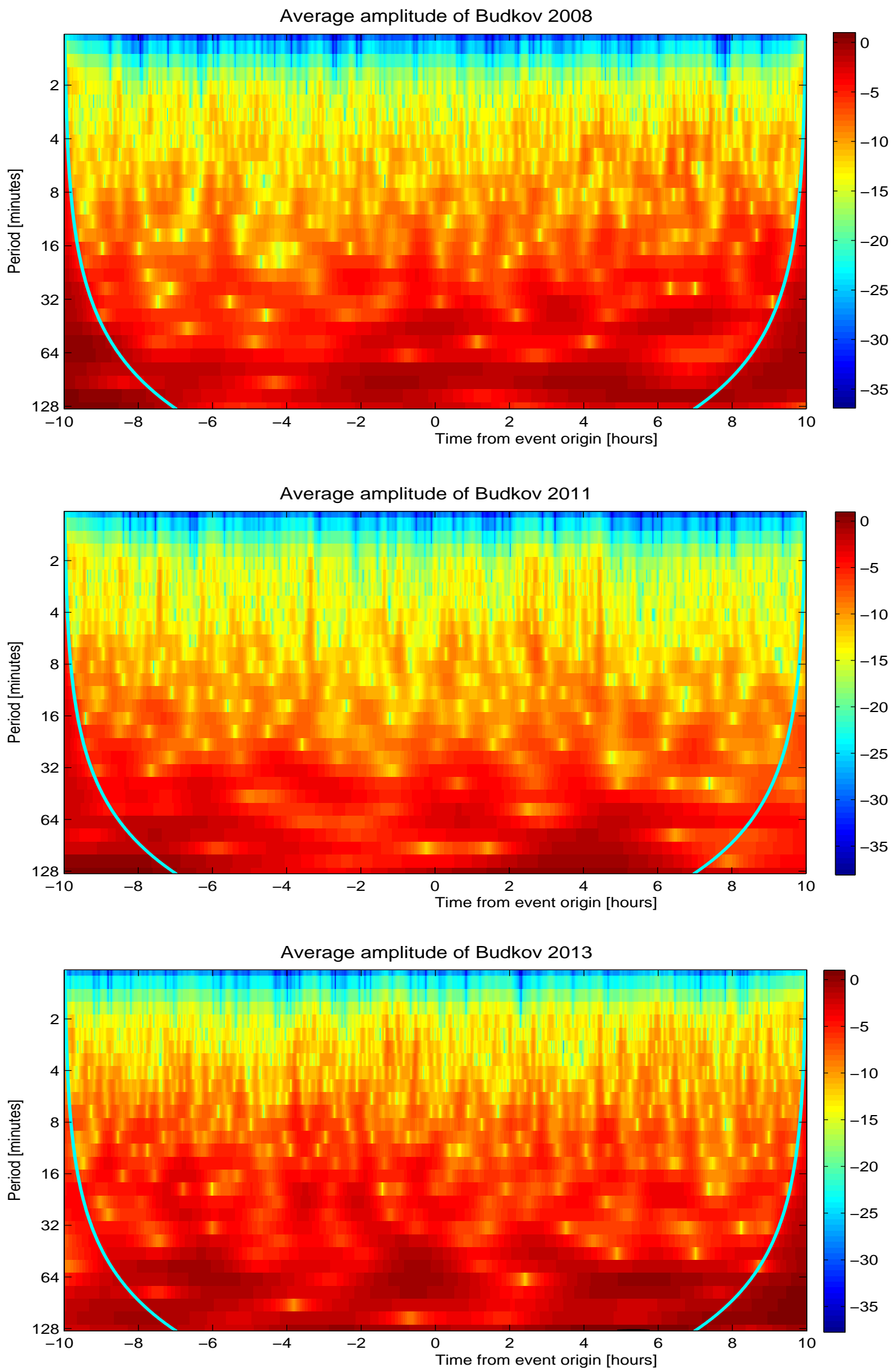

Fig. 8 The same as in Figure 6, but for magnetic signals from station Budkov. Again, as for the seismic signals, no extremes corresponding to the EME signals can be observed, which indicates that observed EME extremes are not excited by outer magnetic field. 


\section{REFERENCES}

Chum, J., Hruška, F., Zedník J. and Laštovička, J.: 2012, Ionospheric disturbances (infrasound waves) over the Czech Republic excited by the 2011 Tohoku earthquake, J. Geophys. Res., 117, A08319. DOI:10.1029/2012JA017767

Chum, J., Diendorfer, G., Šindelářová, T., Baše, J. and Hruška, F.: 2013, Infrasound pulses from lightning and electrostatic field changes: Observation and discussion, J. Geophys. Res. Atm., 118, 10.65310.664. DOI:10.1002/jgrd.50805.

Faber, E., Horálek, J., Boušková, A., Teschner, M., Koch, U. and Poggenburg, J.: 2009, Continuous gas monitoring in theWest Bohemia Earthquake area, Czech Republic: first results, Stud. Geophys. Geod., 53(4), 315-328. DOI: 10.1007/s11200-009-0020-Z

Fraser-Smith, A. C., Bernardi, A., McGill, P. R., Ladd, M. E., Helliwell, R. A., and Villard Jr. and O. G.: 1990, Low-frequency magnetic field measurements near the epicenter of the MS 7.1 Loma Prieta earthquake, Geophys. Res. Lett., 17(9), 1465-1468. DOI: 10.1029/GL017i009p01465

Fischer, T., Horálek, J., Hrubcová, P., Vavryčuk, V., Bräuer, K. and Kämpf, H.: 2013, Intra-continental earthquake swarms in West-Bohemia and Vogtland: A review, Tectonophysics. http://dx.doi.org/10.1016/j.tecto.2013.11.001

Georgiadis, P., Cavouras, D., Sidiropoulos, K., Ninos, K. and Nomocos, C.: 2009, Remote monitoring of electromagnetic signals and seismic event using smart mobile devices, Comput. Geosci., 35, 1296-1308. DOI: 10.1016/j.cageo.2008.07.008

Guglielmi, A., Hayakawa, M., Potapov, A. and Tsegmed, B.: 2006a, Polarization method to detect the coseismic magnetic oscillations, Phys. Chem. Earth Pt. A,B,C, 31(4-9), 299-304.

DOI: $10.1016 /$ j.pce.2006.02.006

Guglielmi, A., Potapov, A., Tsegmed, B., Hayakawa, M. and Dovbnya, B.: 2006b, On the earthquake effects in the regime of ionospheric Alfvén resonances, Phys. Chem. Earth Pt. A,B,C, 31(4-9), 469-472.

DOI: $10.1016 /$ j.pce.2006.02.005

Häge, M. and Joswig, M.: 2008, Microseismic study using small arrays in the swarm area of Nový Kostel: Increased detectability during an inter-swarm period, Stud. Geophys. Geod., 52(4), 661-672. DOI: 10.1007/s11200-008-0042-y

Horálek, J., Fischer, T., Boušková, A. and Jedlička, P.: 2000, The Western Bohemia/Vogtland Region in the light of the Webnet Network, Geophys. Geod., 44(2), 107-125. DOI: 10.1023/A:1022198406514

Horálek, J., Fischer, T., Boušková, A., Michálek, J. and Hrubcová, P.: 2009, The West Bohemian 2008earthquake swarm: When, where, what size and data. Stud. Geophys. Geod., 53:351-358.

DOI: 10.1007/s11200-009-0024-8

Johnston, M.J.S.: 1997, Review of electric and magnetic fields accompanying seismic and volcanic activity, Surv. Geophys., 18, 441-475.

DOI: $10.1023 / \mathrm{A}: 1006500408086$
Kolár̆, P.: 2010, Some possible correlations between electromagnetic emission and seismic activity during West Bohemia 2008 earthquake swarm. Solid Earth 1:9398. DOI: $10.5194 / \mathrm{se}-1-93-2010$

Koláŕ, P., Růžek, B., Boušková, A. and Horálek, J.: 2011, Visualization of the fault slip connected with the West Bohemia earthquake swarms, Acta Geodyn. Geomater., 8, 2, 169-187.

Koláŕ, P. and Růžek, B.: 2012, Finite seismic source parameters inferred from stopping phases for selected events of West Bohemia 2000 swarm. Acta Geodyn. Geomater., 9, 435-447.

Losseva, T. V. and Nemchinov, I. V.: 2005, Earthquake lights and rupture processes, Nat. Hazards Earth Syst. Sci., 5, 649-656. DOI:10.5194/nhess-5-649-2005

Mrlina, J. and Seidl, M.: 2008, Relation of surface movements in West Bohemia to earthquake swarms, Stud. Geophys. Geod., 52(4), 549-566. DOI: $10.1007 / \mathrm{s} 11200-008-0037-8$

Mrlina, J., Kämpf, H., Kroner, C., Mingram, J., Stebich, M., Brauer, A., Geissler, W.H., Kallmeyer, J., Matthes, H. and Seidl, M.: 2009, Discovery of the first Quaternary maar in the Bohemian Massif, Central Europe, based on combined geophysical and geological surveys, Journal of Volcanology and Geothermal Research 182 (1-2), 97-112. DOI: 10.1016/j.jvolgeores.2009.01.027

Růžek, B., Plomerová, J. and Babuška, V.: 2012, Joint inversion of teleseismic $\mathrm{P}$ waveforms and surface-wave group velocities from ambient seismic noise in the Bohemian Massif, Stud. Geophys. Geodet., 56, 107-140. DOI: $10.1007 / \mathrm{s} 11200-010-9089-7$

St-Laurent, F., Derr, J. S. and Freund, F. T.: 2006, Earthquake lights and the stress-activation of positive hole charge carriers in rocks, Phys. Chem. Earth Pt. A,B,C, 31(4-9), 305-312.

DOI: $10.1016 /$ j.pce.2006.02.003

Studia Geohpysica et Geodetica: 2000, (special issue devotes to West Bohemia topics): 44, 2 - 3.

Studia Geohpysica et Geodetica: 2008, (special issue devotes to West Bohemia topics - Part 1): 52, 4.

Studia Geohpysica et Geodetica: 2009, (special issue devotes to West Bohemia topics - Part 2): 53, 3.

Špičák, A.: 2000, Earthquake Swarms and Accompanying Phenomena in Intraplate Regions: A Review, Stud. Geophys. Geod., 44(2), 89-106.

DOI: 10.1023/A:1022146422444

Torrence, C. and Compo, G. P.: 1998, A Practical Guide to Wavelet Analysis, B. Amer. Meteorol. Soc., 79, 6178. DOI: 10.1175/1520-0477(1998)079

wwwWEBNET: 2013, [online] http://www.ig.cas.cz/en/structure/observatories/westbohemia-seismic-network-webnet/, accessed: $13 \mathrm{Feb}$ 2014

Wavelet: 1998, [online] http://paos.colorado.edu/research/wavelets/, accessed: $13 \mathrm{Feb} 2014$ 

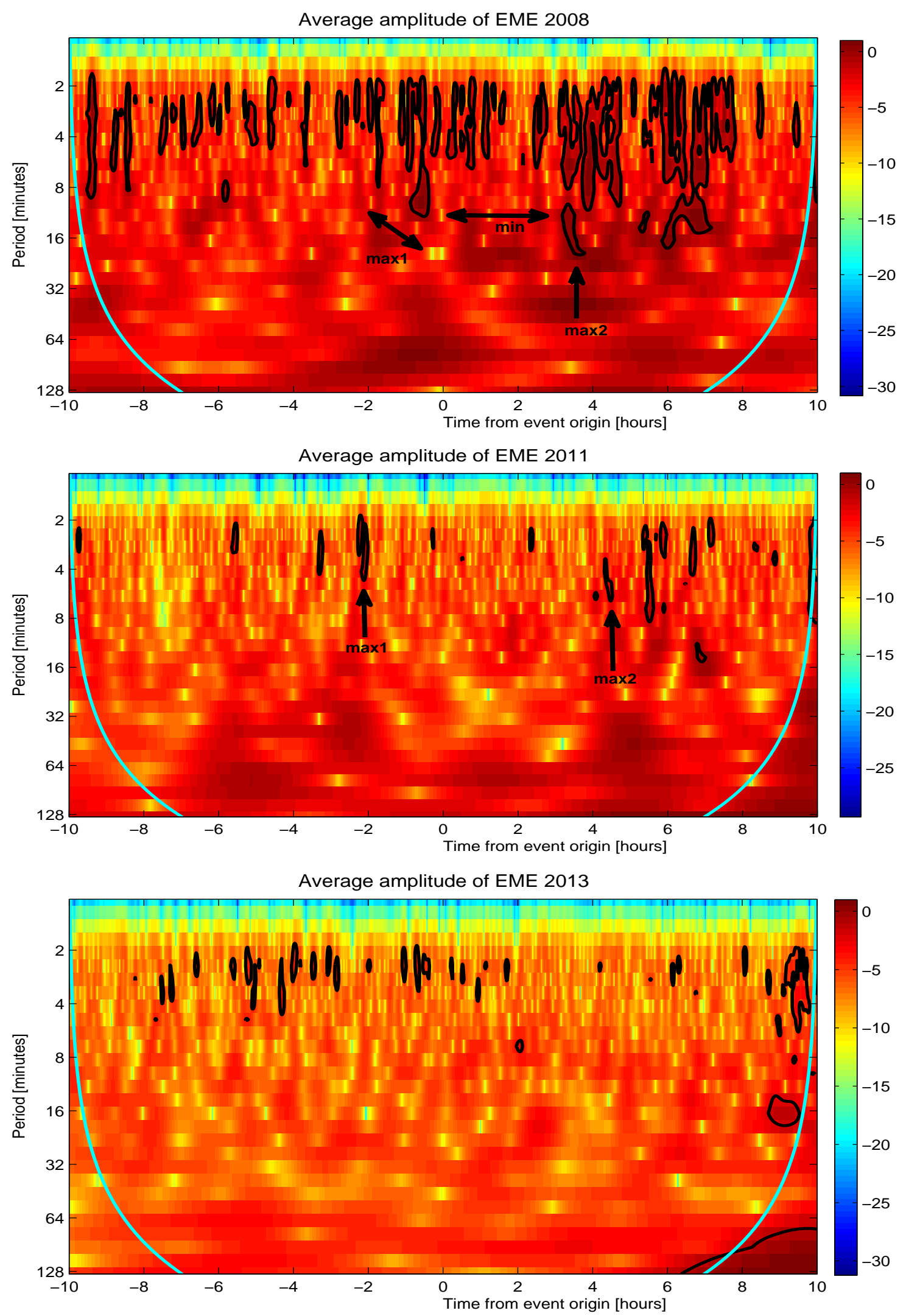

Fig. 6 Wavelet spectra of stacked EME signals a) 2008; b) 2011; c) 2013. There are plotted wavelet spectra of summed EME signal (minute averages of time series are used) in range $d t= \pm 10 \mathrm{~h}$ round the origin times. Algorithm designed by Torrence and Compo (1998) or Wavelet (1998) was used for wavelet spectra construction. The curves in the lower corners determine zones of spectrum reliability, extremes with statistical significance $>0.95$ are marked by black lines (the estimation of probability is based on comparison to the statistical estimation of noise background - see Torrence and Compo, 1998). In Figure 4a (adopted from Kolár, 2010), there are marked position of two maxima and one minimum of activity of 2008 swarm on periods $8-16$ min. Note that the extremes which appear on shorter periods (shorter than $8 \mathrm{~min}$ ) are stochastic and unstable - we do not interpret them. During later swarm (2011) only narrow maxima are observed on higher frequencies $(\max 1$ and $\max 2)$ - Figure $6 \mathrm{~b}$. The latest swarm (2013) does not exhibit any expected extremes pattern - Figure 6c. 